\title{
Pendekatan Model Machine Learning dalam Pemeringkatan Status Sosial Ekonomi Rumah Tangga di Indonesia
}

\author{
(Machine Learning Approaches for Household's Welfare Ranking in Indonesia) \\ Nuri Taufiq ${ }^{1 *}$, Siti Mariyah ${ }^{2}$ \\ ${ }^{1}$ Badan Pusat Statistik RI \\ ${ }^{2}$ Politeknik Statistika STIS \\ Jl. Dr. Sutomo 6-8 Jakarta 10710 Indonesia \\ E-mail: nuritaufik@bps.go.id
}

\begin{abstract}
ABSTRAK
Metode yang digunakan untuk pemeringkatan status sosial ekonomi rumah tangga Basis Data Terpadu adalah dengan memprediksi nilai pengeluaran rumah tangga dengan metode Proxy Mean Testing (PMT). Secara umum metode ini merupakan model prediksi dengan menggunakan teknik regresi. Pilihan model statistik yang digunakan adalah forwardstepwise. Dalam praktiknya diasumsikan bahwa variabel prediktor yang digunakan dalam PMT memiliki korelasi linier dengan variabel pengeluaran. Model PMT secara umum menghasilkan nilai exclusion error dan inclusion error model sebesar 0,29. Penelitian ini bertujuan untuk meningkatkan metodologi dalam mengidentifikasi penduduk miskin khususnya dalam menguji apakah teknik machine learning untuk mengurangi tingkat kesalahan (error) dalam penargetan. Hasil pemodelan menunjukkan bahwa model machine learning menghasilkan nilai rata-rata inclusion error lebih rendah dibandingkan nilai rata-rata exclusion error. Model machine learning bekerja efektif dalam mengurangi inclusion error namun belum cukup sensitif dalam mengurangi exclusion error. Nilai rata-rata inclusion error model machine learning sebesar 0,21 sedangkan nilai rata-rata inclusion error model PMT sebesar 0,29.
\end{abstract}

Kata kunci: PMT, Machine Learning, Inclusion error, Exclusion error

\begin{abstract}
The method used for ranking the socioeconomic status of households in the Integrated Database is to predict the value of household expenditures using the Proxy Mean Testing (PMT) method. In general, this method is a predictive model using a regression technique. The choice of statistical model used is forward-stepwise. In practice it is assumed that the predictor variables used in PMT have a linear correlation with the expenditure variable. The PMT model generally produces an exclusion error and inclusion error model of 0.29. This study aims to improve the methodology for identifying the poor-particularly in testing whether machine learning techniques reduce the error rate in targeting. The modeling results show that the machine learning model produces an average value of inclusion error that is lower than the average value of the exclusion error. Machine learning models work effectively in reducing inclusion errors but are not sensitive enough to reduce exclusion errors. The average value of inclusion error of machine learning model is 0.21 while the average value of inclusion error of PMT model is 0.29 .
\end{abstract}

Keywords: PMT, Machine Learning, Inclusion error, Exclusion error

\section{PENDAHULUAN}

Di dalam upaya penanggulangan kemiskinan, pemerintah merancang beberapa program penanggulangan kemiskinan yang berbeda sesuai dengan tujuannya. Program Keluarga Harapan (PKH) misalnya yang memberikan bantuan bersyarat di bidang pendidikan dasar dan kesehatan, Bantuan Sosial Tunai (BST) selama masa pandemi Covid-19 agar penduduk miskin/rentan tetap bisa memenuhi kebutuhan harian dan masih ada beberapa jenis bantuan lainnya. Berbagai program penanggulangan kemiskinan ini dirancang dan dijalankan oleh Kementerian/Lembaga terkait sesuai dengan bidang tugasnya. Di dalam implementasinya perancang program penanggulangan kemiskinan ini memerlukan Basis Data Terpadu (BDT) yang akurat agar program yang digulirkan dapat tepat sasaran. Basis Data Terpadu adalah data komprehensif yang menyediakan nama, alamat, beserta NIK (Nomor Induk Kependudukan). BDT ini juga memuat beberapa keterangan dasar sosial ekonomi rumah tangga dan individu yang nantinya dapat digunakan untuk memprediksi status sosial ekonomi rumah tangga. Menurut Tim Nasional Percepatan Penanggulangan Kemiskinan (TNP2K), BDT juga dapat digunakan untuk analisis tentang indikator sosial ekonomi bagi 40 persen masyarakat dengan kondisi sosialekonomi terendah sehingga indikator tersebut dapat digunakan untuk merancang program penanggulangan kemiskinan yang relevan, sekaligus memperkiraan anggaran yang dibutuhkan untuk program tersebut (TNP2K, 2017). 
Metode yang digunakan untuk memprediksi status sosial ekonomi rumah tangga pada BDT adalah metode Proxy Mean Test atau biasa dikenal dengan PMT (TNP2K, 2017). Dalam penerapannya, dilakukan penghitungan koefisien setiap parameter PMT, yaitu dengan membuat model prediksi menggunakan teknik regresi. Dengan model prediksi tersebut akan digunakan untuk memprediksi tingkat pengeluaran dari rumah tangga BDT berdasarkan karakteristik rumah tangga yang telah dikumpulkan. Pemilihan model terbaik dilakukan dengan mempertimbangkan beberapa aspek, antara lain nilai koefisein determinasi atau $R$-Square, nilai Adjusted $R$-square, dan nilai inclusion error atau exclusion error hasil prediksi (TNP2K, 2017). Secara umum model PMT ini merupakan model yang mengasumsikan bahwa terdapat hubungan linier antara variabel terikat dengan variabel bebas. Namun dalam kenyataannya asumsi ini tidak sepenuhnya terpenuhi, dimana bisa saja terjadi karakteristik rumah tangga tersebut tidak serta merta memiliki hubungan linier dengan tingkat kesejahteraan. Karakteristik rumah tangga dapat berinteraksi dengan cara yang kompleks, lantai tanah misalnya dapat menunjukkan kemiskinan bagi suatu wilayah tetapi tidak untuk wilayah yang lain, dengan model linier seperti PMT ini maka akan melewatkan perbedaan tersebut (Adelman, 2016).

Machine learning (ML) merupakan bidang penelitian yang menerapkan berbagai disiplin ilmu seperti matematika, statistika, basis data, pemrograman paralel, dll. Pendekatan ini ditandai dengan penggunaan algoritma untuk mengekstrak pengetahuan dari kumpulan data yang besar dan heterogen. ML melakukan learning langsung dari data dan memperkirakan fungsi matematika yang merepresentasikan dari beberapa input, atau belajar menghubungkan satu atau lebih input ke satu atau lebih output untuk dapat merumuskan prediksi pada data baru (Jordan dan Mitchell, 2015). Beberapa contoh learning adalah menggunakan karakteristik rumah dan lingkungan sekitar untuk memprediksi harga rumah dan menggunakan beberapa dokumen yang berlabel topik untuk memprediksi topik pada dokumen-dokumen baru. ML bekerja dengan mendesain algoritma prediksi yang efisien dan akurat. Kualitas model ML diukur tidak hanya ketepatan prediksi namun juga kompleksitas model, waktu untuk membangun dan menggunakan model. ML telah digunakan di berbagai aplikasi seperti klasifikasi teks atau dokumen, pemrosesan bahasa alami (natural language processing), pemrosesan suara (speech recognition), pemrosesan gambar (image processing), dll. Kemampuan learning berkaitan dengan kemampuan forecast. Artificial neural networks menawarkan kinerja yang baik dalam univariate forecasting, yaitu ketika ingin memprediksi perilaku variabel dari suatu sistem yang berkembang dari waktu ke waktu berdasarkan tren masa lalu, dan dalam multivariate analysis, ketika mencoba untuk memprediksi tren dari suatu sistem (Di Franco dan Santurro, 2021). ML menyediakan metode terstruktur untuk mencari serangkaian fungsi yang sangat luas guna memaksimalkan kekuatan dari model prediksi. Beberapa metode seperti teknik Lasso, adalah mirip dengan regresi linier tetapi memungkinkan banyak kompleksitas yang lebih besar.

Penelitian ini akan memanfaatkan keunggulan dari ML untuk memprediksi pengeluaran konsumsi rumah tangga sebagai ukuran kesejahteraan rumah tangga berdasarkan karakteristik yang dimiliki oleh rumah tangga tersebut. Model PMT saat ini secara umum menghasilkan nilai exclusion error dan inclusion error model sebesar 0,29. Penelitian ini akan membangun dan mengevalusi kinerja beberapa model ML yang berbeda dalam memprediksi tingkat kesejahteraan rumah tangga. Selain itu penelitian ini juga mengidentifikasi pola karakteristik rumah tangga pada kelompok rumah tangga miskin dan tidak miskin dan menganalisis pola prediksi ML.

\section{METODE}

Secara umum tujuan dari pemodelan dalam penelitian ini adalah untuk memberikan prediksi tingkat kesejahteraan rumah tangga melalui pendekekatan pada estimasi nilai pengeluaran rumah tangga. Proses pemodelan yang dilakukan menggunakan data Survei Sosial Ekonomi Nasional (Susenas) dengan keseluruhan sampel, meskipun target dari rumah tangga Basis Data Terpadu adalah rumah tangga dengan tingkat kesejahteraan 40 persen terbawah secara nasional. Menurut TNP2K (2017) bahwa jika proses pemodelan hanya menggunakan sebagian rumah tangga terbawah dari data Susenas, maka akurasi model akan berkurang. Sehingga sampel seluruh rumah tangga diperlukan agar model yang dibangun dapat mengenali variabel mana yang mampu membedakan antara pengeluaran rumah tangga miskin dan rumah tangga yang tidak miskin. Atau apabila sampel yang digunakan merupakan rumah tangga miskin saja atau sebaliknya, model akan sulit menemukan variabel yang menjadi pembeda secara signifikan. Data Susenas yang digunakan adalah Susenas kondisi Maret. Untuk memperkuat jumlah sampel pemodelan, dilakukan penggabungan (pooling) data Susenas Maret dari tahun 2016 sampai dengan tahun 2020 dengan jumlah sampel gabungan mencapai 1.533.746 rumah tangga. Hal ini dilakukan untuk menambah jumlah observasi dan memungkinkan estimasi pemodelan sampai dengan level kabupaten/kota. Pemodelan dilakukan pada 514 kabupaten/kota di seluruh Indonesia. Setiap kabupaten/kota akan diterapkan model pemeringkatan status kesejahteraan rumah tangga dengan model PMT 
dan model ML, sehingga untuk analisis perbandingan model dapat dilihat untuk masing-masing kabupaten/kota dengan melihat performa model dari setiap kabupaten/kota.

\section{Pemilihan Variabel}

Pemilihan kandidat variabel yang digunakan didasarkan pada dua data. Data pertama adalah data Susenas yang memiliki variabel pengeluaran per kapita serta karakteristik sosial ekonomi rumah tangga. Data kedua adalah Basis Data Terpadu yang menjadi data target untuk dilakukan prediksi pengeluaran per kapita rumah tangga. Kedua data ini memiliki overlapped variables yaitu sejumlah variabel dengan jenis, karakteristik dan tipe yang sama. Sehingga overlapped variables inilah yang digunakan dalam pemodelan PMT maupun ML. Secara umum prinsip pemilihan variabel penjelas yang digunakan adalah karakteristik rumah tangga atau anggota rumah tangga yang dapat diamati untuk memperkirakan pendapatan atau konsumsi mereka (World Bank, 2015). Selain itu variabel penjelas yang digunakan dalam penelitian ini juga merujuk pada variabel yang digunakan oleh TNP2K (2017) dalam melakukan pemodelan PMT pada kegiatan Pemutakhiran Basis Data Terpadu (PBDT) 2015 yang dilakukan oleh BPS. Variabel ini juga secara umum digunakan pada penelitian sebelumnya terkait model PMT (Sharif, 2009; Sebastian et al ., 2018). Dalam pemodelan ini juga digunakan Indeks Kesulitan Geografis (IKG) yang diolah dari data Potensi Desa (PODES) 2018, hal ini dilakukan karena kondisi geografis juga berpengaruh pada kesejahteraan rumah tangga sehingga diperlukan faktor koreksi wilayah.

\section{Variabel Penjelas}

Variabel penjelas yang digunakan dalam pemodelan adalah variabel karakteristik rumah tangga yang relevan untuk memprediksi pengeluaran rumah tangga. Secara umum, mekanisme yang digunakan adalah sebagai berikut:

a. Karakteristik rumah tangga yang tidak hanya mengutamakan karakteristik kepala rumah tangga, tetapi juga mengikutsertakan karakteristik anggota rumah tangga. Semua variabel karakteristik rumah tangga dibuat menjadi dummy variable, sedangkan variabel karakteristik anggota rumah tangga dibuat menjadi jumlah anggota rumah tangga dengan karakteristik tersebut,

b. Dilakukan pengelompokan ulang variabel dengan metode Tukey. Metode Tukey menilai apakah terdapat perbedaan yang signifikan antara kategori dalam variabel. Variabel yang secara statistik tidak berbeda dikelompokkan ke dalam satu kategori yang sama. Sebagai contoh, variabel status kepemilikkan bangunan yang awalnya memiliki tujuh kategori dikelompokkan ulang menjadi empat kategori, yaitu: milik sendiri, bebas sewa/lainnya, sewa/kontrak, dan dinas.

Tabel 1. Klasifikasi Variabel Penjelas Menurut Kelompok

\begin{tabular}{ll}
\hline Kelompok Variabel & \multicolumn{1}{c}{ Variabel } \\
\hline Demografi & Jumlah ART dengan rentang usia tertentu \\
Pendidikan & Persentase ART dalam ruta yang menamatkan jenjang pendidikan tertentu \\
Pekerjaan & Sektor Pekerjaan, Status dalam Pekerjaan \\
Karakteristik & Jenis Lantai, Jenis Atap, Jenis Dinding, Penerangan Utama, Sumber Air Minum, \\
Perumahan & Sanitasi, Status Kepemilikan Rumah \\
Kepemilikan Aset & Mobil, Komputer/Laptop, Kulkas, Emas, Perahu Motor, Sepeda Motor, Perahu, \\
& Telefon Rumah \\
Kewilayahan & Indeks Kesulitan Geografis (IKG) \\
\hline
\end{tabular}

\section{Variabel Respon}

Variabel respon dalam pemodelan adalah pengeluaran perkapita rumah tangga. Pada tahap awal pemodelan, bentuk distribusinya dapat dilihat pada Gambar 1. Gambar pada sisi kiri adalah hasil distribusi yang terlihat skewed (condong). Akibatnya, pada gambar ini tidak terlihat perbedaan pengeluaran antara rumah tangga kelompok bawah dengan rumah tangga kelompok atas. Untuk itu, variabel pengeluaran rumah tangga harus dibuat transformasi ke dalam log sebagaimana yang terlihat pada gambar di sisi kanan. 

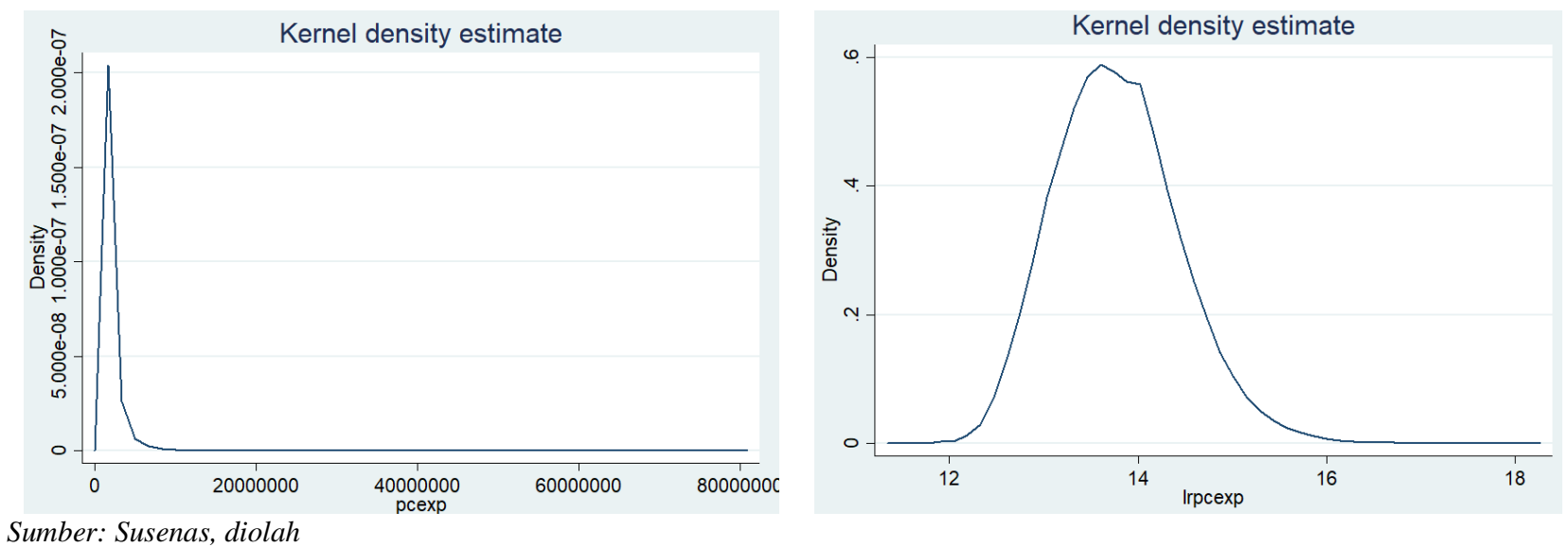

Gambar 1. Perbandingan Bentuk Distribusi Pengeluaran Perkapita

\section{Kriteria Pemilihan Model}

Menurut World Bank (2015) setelah memilih model, perlu juga dilihat seberapa baik model tersebut mampu untuk mengidentifikasi rumah tangga miskin. Salah satu mekanismenya adalah dengan membandingkan hasil prediksi tingkat konsumsi dari model dengan tingkat konsumsi rumah tangga yang aktual (dari survei). Misalnya dianggap bahwa yang terasuk rumah tangga miskin adalah mereka yang berada pada 40 persen terbawah tingkat konsumsinya, jika hasil model tidak mengklasifikasikan rumah tangga tersebut masuk dalam kelompok 40 persen terbawah, maka ini yang disebut sebagai exclusion error, sebaliknya apabila rumah tangga tersebut sebenarnya adalah kelompok diatas kelompok 40 persen terbawah tetapi model mengklasifikasi sebagai rumah tangga miskin maka ini yang disebut dengan inclusion error.

Prediksi yang dihasilkan model statistik tidak sempurna, dimana masih terdapat error yang mungkin akan terjadi. Inclusion error adalah kesalahan pemodelan yang menyebabkan nantinya rumah tangga yang tidak berhak menerima manfaat (kelompok atas) justru menjadi penerima manfaat (masuk kelompok bawah). Sementara itu, exclusion error adalah kesalahan pemodelan yang menyebabkan rumah tangga yang berhak menerima manfaat (kelompok bawah) tidak menerima bantuan sosial (masuk kelompok atas).

\section{Proxy Means Test}

Proxy Means Test (PMT) merupakan suatu metode yang digunakan untuk memprediksi konsumsi rumah tangga berdasarkan informasi karakteristik rumah tangga. Menurut World Bank (2015) PMT biasanya dipahami sebagai penggunaan karakteristik rumah tangga atau anggota rumah tangga yang dapat diamati untuk memperkirakan pendapatan atau konsumsi mereka ketika pendapatan lainnya (slip gaji, pengambilan pajak) tidak tersedia atau tidak dapat diandalkan. Model PMT biasanya dibangun berasal dari data survei rumah tangga yang mencatat dua hal yaitu terkait karakteristik rumah tangga, seperti jenis rumah, kepemilikan aset, komposisi anggota rumah tangga menurut umur, jenis kelamin, dan jenis pekerjaannya dan terkait dengan tingkat kesejahteraannya yang biasanya diukur dari tingkat konsumsi rumah tangga (World Bank, 2015).

Tahap pertama dalam pemodelan PMT adalah memilih beberapa variabel yang memiliki korelasi erat dengan tingkat kesejahteraan yang biasa didekati dengan variabel pengeluaran. Variabel yang dipilih harus relatif sulit bagi rumah tangga untuk memanipulasi dan juga variabel tersebut mudah untuk diukur atau diamati. Setelah pemilihan variabel, langkah berikutnya adalah mengestimasi masing-masing variabel dengan menggunakan metode statistik. Salah satu metode yang umum digunakan adalah analisis regresi dimana memodelkan tingkat pengeluaran rumah tangga berdasarkan variabel-variabel yang telah dipilih. Selanjutnya, setelah diperoleh estimasi tingkat pengeluaran rumah tangga maka dilakukan pemeringkatan guna memperoleh informasi mengenai tingkatan kesejahteraan rumah tangga tersebut relatif terhadap rumah tangga yang lain (Coady, Grosh, \& Hoddinott, 2004).

Pemodelan PMT akan menghasilkan koefisien regresi untuk setiap variabel. Koefisien ini menggambarkan besaran pengaruh variabel terhadap tingkat pengeluaran per kapita dengan persamaan sebagai berikut

$\ln Y_{i}=\hat{\alpha}+X_{i} \hat{\beta}+\varepsilon_{i}$

dimana:

$\ln Y=$ variabel respon $\log$ pengeluaran per kapita

$\alpha=$ konstanta 
$X \quad=$ variable penjelas

$\beta=$ koefisien regresi untuk kelompok varibel penjelas $X$ pada rumah tangga ke-i

$\varepsilon \quad=$ error

Pemangkatan eksponensial jumlah koefisien signifikan menghasilkan nilai nominal prediksi pengeluaran per kapita dengan persamaan berikut

$\widehat{Y}_{l}=\exp \left(\hat{\alpha}+X_{i} \hat{\beta}\right)$

Hubungan antara variabel terpilih dengan variabel respon dapat dilakukan dengan membandingkan hasil regresi dengan variabel yang berbeda yang disertakan atau dihilangkan dari model. Selain itu juga dapat dilakukan dengan membandingkan hasil $R$-Square dan nilai koefisien yang signifikan untuk model yang berbeda (World Bank, 2015).

\section{Machine Learning}

Machine learning atau sering dikenal dengan ML merupakan salah satu cabang ilmu komputer yang berkembang pesat dalam beberapa dekade terakhir. Machine learning secara luas dapat didefinisikan sebagai metode komputasi yang menggunakan pengalaman untuk meningkatkan performa atau membuat prediksi menjadi akurat. Pengalaman bermakna sekumpulan data atau informasi yang akan dipelajari oleh algoritma (mesin). Contoh sederhana pengunaan machine learning adalah untuk mengklasifikasikan suatu penyakit tumor dalam kategori jinak atau ganas. Pengalaman untuk kasus ini adalah data rekam medis pasien-pasien yang mengalami tumor beserta kategori dan tingkat keparahan/keganasan yang akan dipelajari algoritma. Pembelajaran ini sering dikenal dengan istilah training. Training akan menghasilkan model yang kemudian diuji melalui sekumpulan data uji (testing set) untuk diketahui performanya.

\section{Algoritma Machine Learning}

a. Algoritma Multivariate Adaptive Regression Splines (MARS)

Kelebihan dari model linear adalah kemudahan dan kecepatan dalam perhitungan/komputasi dan kemudahan dalam menerjemahkan koefisien-koefisien yang dihasilkan. Namun, model linear memiliki asumsi-asumsi yang kuat dan seringkali asumsi tersebut tidak bisa terpenuhi yang berakibat pada menurunnya akurasi prediksi. Multivariate Adaptive Regression Splines (MARS) merupakan salah satu metode regresi nonparametrik yang pertama kali dipopulerkan oleh Friedman (1991). Model MARS bermanfaat untuk mengatasi permasalahan data yang berdimensi tinggi. Model MARS juga memiliki lebih banyak kekuatan dan fleksibilitas untuk memodelkan hubungan yang hampir aditif atau melibatkan interaksi paling banyak dalam beberapa variabel, dan menghasilkan model kontinu dengan turunan kontinu. Model MARS menyediakan pendekatan yang lebih mudah. untuk menangkap hubungan non-linear pada data dengan mengukur titik potong (cutpoints) yang serupa dengan step functions. Prosedur menaksir setiap poin data untuk setiap predictor dan membuat sebuah model regresi linear dengan dengan variabel-variabel kandidat.

\section{b. Algoritma K-Nearest Neighbors}

Algoritma K-Nearest Neighbors (KNN) adalah sebuah metode untuk melakukan klasifikasi terhadap objek yang berdasarkan dari data pembelajaran yang jarkanya paling dekat dengan objek tersebut (Avelita, 2016). KNN merupakan algoritma supervised learning dimana hasil dari query instance yang baru diklasifikan berdasarkan mayoritas dari kategori pada algoritma KNN. Dimana kelas yang paling banyak muncul yang nantinya akan menjadi kelas hasil dari klasifikasi. Tidak seperti metode-metode lain, KNN adalah sebuah algoritma yang bersifat memory-based dan tidak dapat disummari dengan bentuk sebuah closed-form model. Artinya, data latih tetap dibutuhkan saat prediksi dilakukan. Konsekuensinya, KNN dikenal juga sebagai lazy learner dan secara komputasi bisa menjadi tidak efisien karena proses pembelajaran dilakukan bersamaan dengan proses prediksi. Algoritma KNN mengidentifikasi $k$-observasi yang mirip atau paling dekat dengan observasi yang akan diprediksi dan menggunakan rata-rata nilai respon (untuk regresi) atau nilai respon yang sering muncul (untuk klasifikasi) dari $k$-observasi sebagai hasil prediksi. Misalkan pada kasus prediksi/estimasi nilai pengeluaran konsumsi rumah tangga berdasarkan variabel aset, perumahan, pendidikan, pekerjaan dan variabel demografi. Maka, rumah tangga yang akan diprediksi besaran pengeluaran konsumsinya, akan dicari beberapa rumah tangga lain dari data yang ada, yang memiliki kemiripan dari sisi variabel aset, perumahan, pendidikan, pekerjaan, dan variabel demografi.

\section{c. Algoritma Decision Tree}

Decision tree merupakan salah satu teknik yang dapat digunakan untuk melakukan klasifikasi terhadap sekumpulan objek atau record. Teknik ini terdiri dari kumpulan decision node, dihubungkan oleh cabang, bergerak ke bawah dari root node sampai berakhir di leaf node (Yogi, 2007). Pengembangan decision tree 
dimulai dari root node, berdasarkan konvensi ditempatkan di bagian atas diagram decision tree, semua atribut dievaluasi pada decision node, dengan tiap outcome yang mungkin menghasilkan cabang. Tiap cabang dapat masuk baik ke decision node yang lain ataupun ke leaf node. Persyaratan yang harus dipenuhi dalam penerapan algoritma decision tree: 1. Algoritma decision tree merepresentasikan supervised learning, dan oleh karena itu membutuhkan variabel target preclassified. 2. Training data set harus kaya dan bervariasi. 3. Kelas atribut target harus diskrit.

\section{d. Algoritma Bagging}

Bagging singkatan dari Bootstrap Aggregating yang dirancang oleh Breiman (1996). Bootstrap adalah bagian dari prosedur penarikan contoh (sampling), yang menghasilkan $\mathrm{n}$ contoh bootstrap dengan mengambil sampel dengan pengembalian pada data asli. Bagging merupakan algoritma ensemble pertama yang didisain untuk meningkatkan stabilitas dan akurasi algoritma klasifikasi dan regresi. Bagging merupakan sebuah metode yang menghasilkan berbagai versi model dan melakukan prediksi atau estimasi dengan merata-ratakan berbagai versi model tersebut (Breiman, 1996). Bagging bekerja dengan konsep mengurangi varians dan meminimalkan overfitting. Meskipun sering diterapkan pada algoritma decision tree, bagging bisa juga diaplikasikan pada algoritma lain.

\section{Skema Simulasi Machine Learning}

Pada pemodelan machine learning ini, digunakan algoritma-algoritma yang terdiri dari Multivariate Adaptive Regression Splines (MARS), K-Nearest Neighbors, Decision Tree, dan Bagging. Skema simulasi sebagai berikut:

a. Model dibangun pada level kabupaten/kota dengan data Pooling Susenas dari tahun 2016 sampai dengan tahun 2020. Variabel penjelas (independent variables) adalah dibentuk dari informasi demografi, aset dan kepemilikannya, pencapaian pendidikan, ketenagakerjaan, dan kondisi tempat tinggal dan status kepemilikannya.

b. Shuffling dilakukan pada dataset agar terdapat perwakilan data setiap tahun. Kemudian data dibagi menjadi dua bagian, yaitu 80 persen data untuk training set dan 20 persen data untuk testing set.

c. Model kemudian dibangun pada data training set dengan proses validasi menggunakan cross validation sebanyak 10 kali. Pembangunan model dilakukan tanpa menggunakan design weight.

d. Model memprediksi nilai pengeluaran perkapita (lrpcexp) baik pada testing set maupun training set.

e. Rumah tangga diurutkan dan dikelompokkan berdasarkan desil nilai lrpcexp. Rumah tangga yang berada pada desil 1-4 menjadi kelompok rumah tangga pertama. Kelompok rumah tangga pertama adalah kelompok 40 persen terbawah dan dianggaap sebagai kelompok rumah tangga kandidat penerima bantuan. Sedangkan rumah tangga yang berada pada desil 5-10 menjadi kelompok rumah tangga kedua dan dianggap sebagai kelompok rumah tangga dengan kesejahteraan menengah atas.

f. Performa model dihitung berdasarkan nilai sensitivity, specificity, inclusion error, dan exclusion error. Inclusion error menyatakan persentase rumah tangga kelompok kedua yang masuk atau diprediksi sebagai kelompok rumah tangga pertama sebaliknya exclusion error menyatakan persentase rumah tangga kelompok pertama yang keluar atau diprediksi sebagai kelompok rumah tangga kedua.

\section{HASIL DAN PEMBAHASAN}

Pemodelan dilakukan pada 514 kabupaten/kota di seluruh Indonesia. Setiap kabupaten/kota menghasilkan empat jenis model dan performa sehingga total model machine learning yang dihasilkan adalah sebanyak 2.056 model. Karena keterbatasan dalam mengulas satu per satu secara detail, maka performa model akan diulas secara umum dan secara detail hanya pada 2 kabupaten/kota terpilih.

Tabel 2. Statistik Nilai Inclusion dan Exclusion Error pada Masing-Masing Wilayah Hasil ML

\begin{tabular}{llccc}
\hline \multicolumn{1}{c}{ Wilayah } & Type Error & Nilai Minimum & Rata-rata & Nilai Maksimum \\
\hline Seluruh Wilayah & Inclusion Error & 0,11 & 0,21 & 0,31 \\
& Exclusion Error & 0,16 & 0,32 & 0,46 \\
Kabupaten & Inclusion Error & 0,11 & 0,22 & 0,31 \\
& Exclusion Error & 0,16 & 0,33 & 0,46 \\
\multirow{3}{*}{ Kota } & Inclusion Error & 0,13 & 0,19 & 0,26 \\
& Exclusion Error & 0,19 & 0,28 & 0,39 \\
\hline
\end{tabular}

Sumber: Susenas 2016-2020, diolah 
Tabel 2 menunjukkan bahwa baik di wilayah kabupaten maupun di kota, nilai exclusion error lebih tinggi dibandingkan nilai inclusion error. Artinya model machine learning cenderung lebih banyak memprediksi nilai ln real percapita expenditure lebih tinggi daripada nilai yang terdata dibandingkan memprediksi lebih rendah. Sehingga lebih banyak rumah tangga yang keluar dari kelompok 40 persen terbawah dibandingkan rumah tangga 60 persen ke atas yang masuk. Secara umum model juga bekerja lebih baik pada daerah kota dibandingkan daerah kabupaten. Hal ini diduga dikarenakan variabel penjelas yang dipakai untuk memprediksi nilai $\ln$ real percapita expenditure tidak memiliki varians yang besar atau tidak berbeda signifikan antara rumah tangga dengan pengeluaran ril perkapita $(l n)$ tinggi dan rendah terutama di daerah kabupaten.

Tabel 3. Statistik Nilai Inclusion dan Exclusion Error pada Masing-Masing Wilayah Hasil PMT

\begin{tabular}{llccc}
\hline \multicolumn{1}{c}{ Wilayah } & \multicolumn{1}{c}{ Error } & Nilai Minimum & Rata-rata & Nilai Maksimum \\
\hline Seluruh Wilayah & Inclusion Error & 0,17 & 0,29 & 0,45 \\
& Exclusion Error & 0,18 & 0,29 & 0,45 \\
Kabupaten & Inclusion Error & 0,17 & 0,30 & 0,45 \\
& Exclusion Error & 0,18 & 0,30 & 0,45 \\
\multirow{3}{*}{ Kota } & Inclusion Error & 0,19 & 0,26 & 0,36 \\
& Exclusion Error & 0,19 & 0,26 & 0,36 \\
\hline
\end{tabular}

Sumber: Susenas 2016-2020, diolah

Jika dibandingkan dengan hasil pemodelan dengan metode PMT (Tabel 3) maka secara umum dapat dilihat bahwa nilai rata-rata exclusion error model PMT cenderung sedikit lebih kecil jika dibandingkan dengan hasil Machine Learning. Namun untuk nilai inclusion error hasil PMT cenderung lebih besar jika dibandingkan dengan hasil Machine Learning. Untuk memahami lebih baik bagaimana hubungan antara variabel penjelas, nilai pengeluaran per kapita dan performa model machine learning maka analisis lebih mendalam dilakukan pada beberapa 2 kabupaten/kota yaitu Kabupaten Simeulue dan Kota Jakarta Pusat. Dua wilayah ini dipilih sebagai representasi wilayah perdesaan dan perkotaan yang menunjukkan adanya perbedaan performa model yang juga dipengaruhi oleh kondisi data dasar (Susenas) yang digunakan untuk membangun model.

\section{Provinsi Aceh - Kabupaten Simeulue}

Tabel 4. Performa Model Machine Learning di Kabupaten Simeulue

\begin{tabular}{ccccc}
\hline Model & Sensitivity & Specificity & Exclusion_Error & Inclusion_Error \\
\hline Multivariate Adaptive Regression & 0,716578 & 0,807971 & 0,283422 & 0,192029 \\
K-Nearest Neighbor & 0,721925 & 0,811594 & 0,278075 & 0,188406 \\
Decision Tree & 0,668449 & 0,775362 & 0,331551 & 0,224638 \\
Bagging & 0,684492 & 0,786232 & 0,315508 & 0,213768 \\
\hline
\end{tabular}

Sumber: Susenas 2016-2020, diolah

Berdasarkan Tabel 4 di atas, bahwa Model K-Nearest Neighbor mampu menghasilkan inclusion error dan exclusion error lebih rendah dibandingkan model lain. Nilai exclusion error lebih tinggi dari inclusion error. Dengan model K-Nearest Neighbor, inclusion error bisa berkurang menjadi 0,188 namun exclusion error masih melebihi 0,25 .

Pada Gambar 2 menunjukkan bahwa terjadi pengurangan rentang lrpcexp setelah diprediksi model. Nilai lrpcexp sebenarnya (aktual) memiliki rentang dari 12,37 hingga 15,22 namun prediksi model K-Nearest Neighbor nilai lrpcexp memiliki rentang yang lebih kecil yaitu dari 12,89 hingga 14,67. Terlihat bahwa pada desil 9 dan 10, model cenderung under prediction artinya nilai lrpcexp prediksi lebih rendah dibandingkan nilai lrpcexp sebenarnya. Sedangkan pada desil 1 sampai desil 4, model cenderung over prediction pada sebagian besar data artinya nilai lrpcexp prediksi lebih tinggi dibandingkan nilai lrpcexp sebenarnya. Nilai lrpcexp pada desil 4 sebesar 13,36. Gambar 2 menampilkan bahwa sebagian data pada desil 1 hingga 4 diprediksi melebihi 13,36. Sehingga banyak rumah tangga yang keluar dari kelompok rumah tangga 40 persen terendah. Hal diduga terjadi karena tidak adanya perbedaan siginifikan pada variabel penjelas antara kelompok rumah tangga 40 persen terendah dan kelompok rumah tangga 60 persen teratas. 


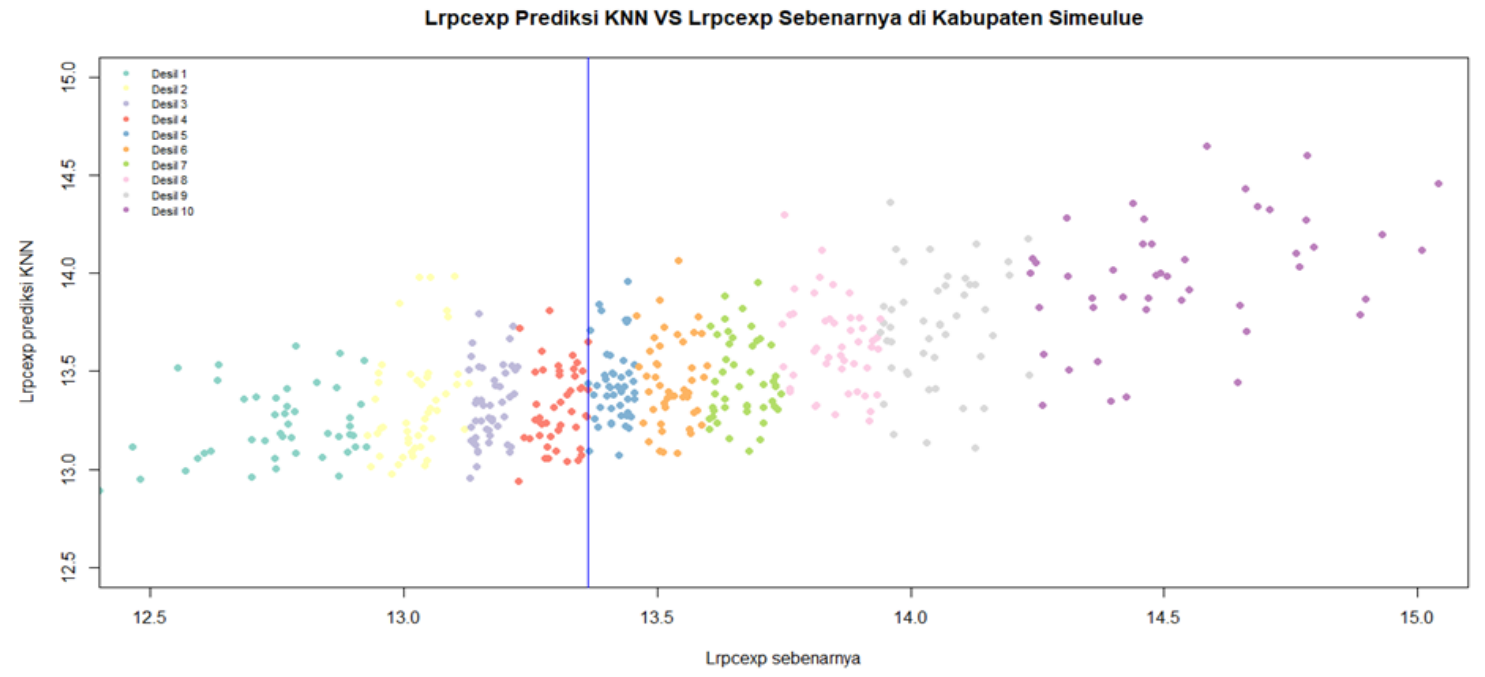

Sumber: Susenas, diolah

Gambar 2. Perbandingan Lrpcexp Prediksi KNN dan Lrpcexp Sebenarnya di Kab. Simeulue
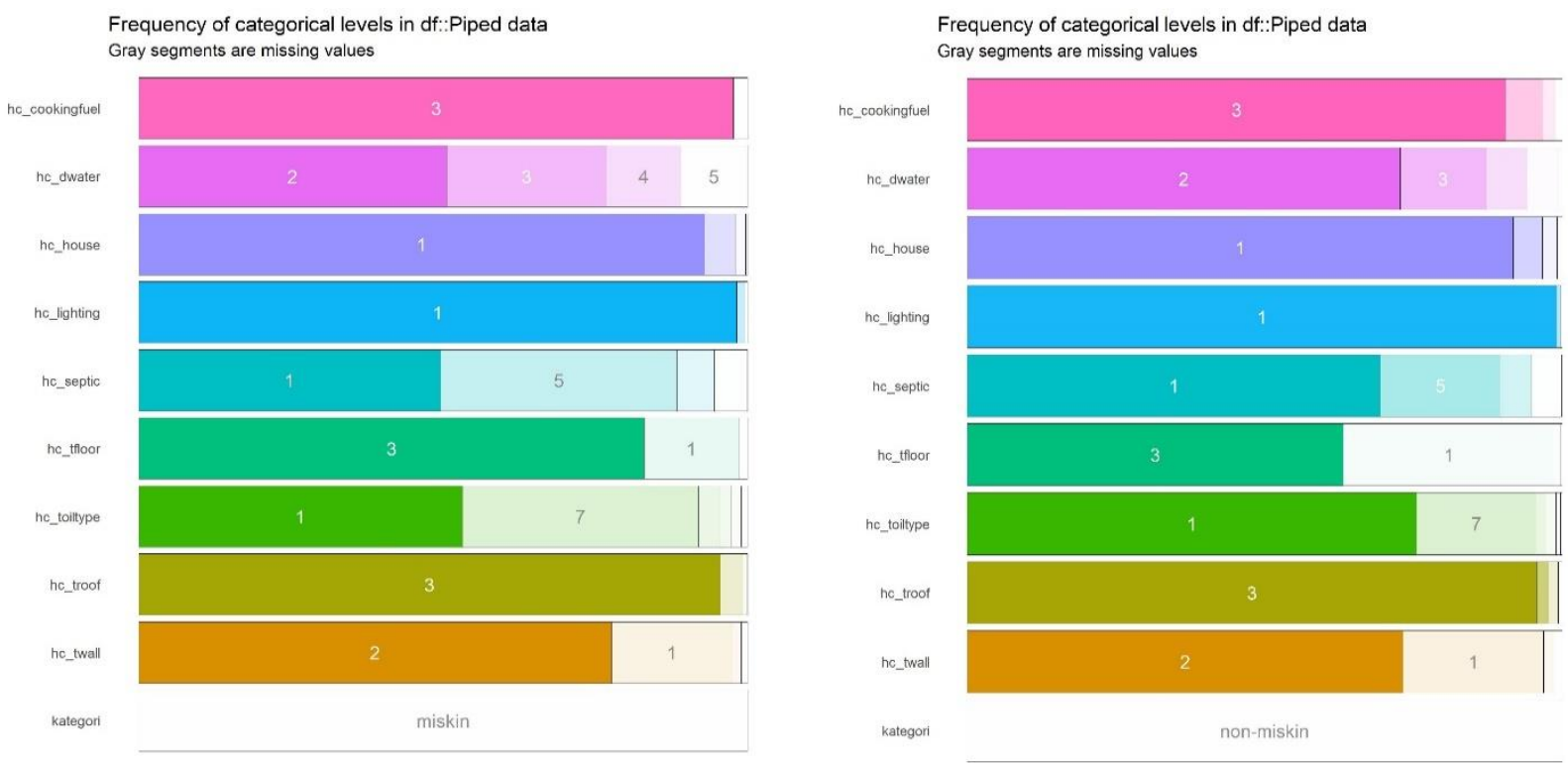

Sumber: Susenas, diolah

Gambar 3. Nilai Variabel Karakteristik Tempat Tinggal Pada Kelompok 40 Persen Terbawah dan 60 Persen teratas di Kabupaten Simeulue

Gambar 3 menunjukkan variabel karakteristik tempat tinggal pada kelompok 40 persen terbawah dan 60 persen teratas. Semua variabel karakteristik tempat tinggal memiliki nilai dengan proporsi yang sangat mirip antar kedua kelompok kecuali pada variabel sumber air minum ( $\left.h c_{-} d w a t e r\right)$. Terlihat bahwa sumber air minum pada kelompok 40 persen terbawah lebih beragam. Jika pada kelompok 40 persen terbawah sumber air minum lebih beragam maka pada kelompok 60 persen teratas sumber air minum didominasi oleh air isi ulang/leding dan sumur bor/pompa.

\section{Provinsi DKI - Kota Jakarta Pusat}

Tabel 5. Performa Model Machine Learning di Kota Jakarta Pusat

\begin{tabular}{crrrr}
\hline Model & Sensitivity & \multicolumn{1}{c}{ Specificity } & Exclusion_Error & \multicolumn{1}{c}{ Inclusion_Error } \\
\hline Multivariate Adaptive Regression & 0.775974 & 0.853212 & 0.224026 & 0.154312 \\
K-Nearest Neighbor & 0.766234 & 0.843478 & 0.233766 & 0.156522 \\
Decision Tree & 0.688312 & 0.791304 & 0.311688 & 0.208696 \\
Bagging & 0.766234 & 0.843478 & 0.233766 & 0.156522 \\
\hline
\end{tabular}

Sumber: Susenas 2016-2020, diolah 
Berdasarkan Tabel 5, menunjukkan bahwa model di Kota Jakarta Pusat memiliki nilai inclusion error paling kecil dibandingkan daerah-daerah lain. Nilai inclusion error sebesar 0,15 dan exclusion error sebesar 0,22 .

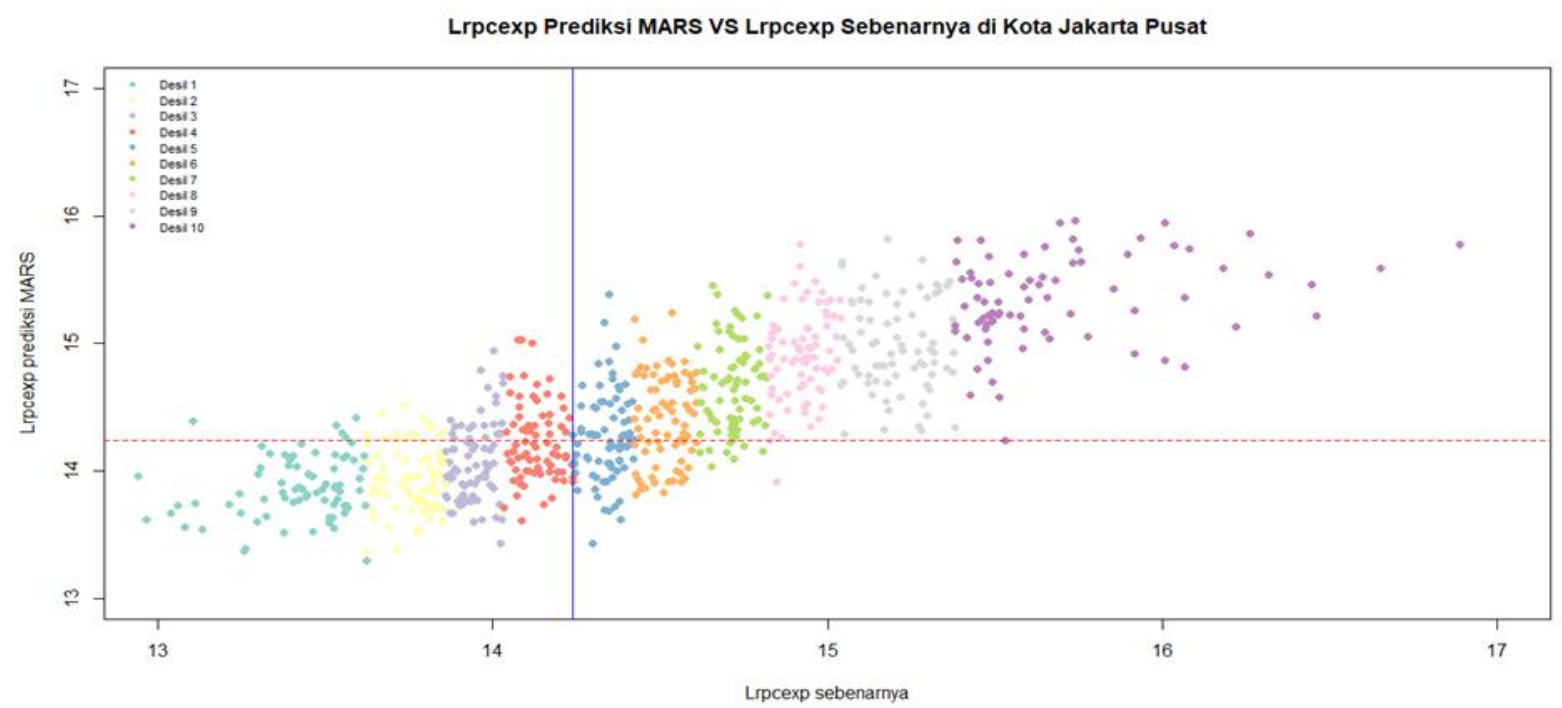

Sumber: Susenas, diolah

Gambar 4. Perbandingan Lrpcexp Prediksi MARS dan Lrpcexp Sebenarnya di Kota Jakarta Pusat

Jika dibandingkan dengan kabupaten/kota yang lain, Kota Jakarta Pusat memiliki rentang nilai pengeluaran ril per kapita $(l n)$ yang lebih besar berkisar pada 12,62 hingga 16,89. Model MARS memprediksi pengeluaran ril per kapita $(l n)$ dengan rentang nilai yang lebih kecil yaitu 13,29-15,96. Gambar 4 menunjukkan sebagian kecil rumah tangga pada kelompok non miskin mengalami under prediction hingga di bawah nilai maksimum pengeluaran ril per kapita (In) desil 4 yaitu di bawah 14,24. Gambar 4 juga menunjukkan bahwa kelompok desil 2, 3, dan 4 masih rentan mengalami over prediction.
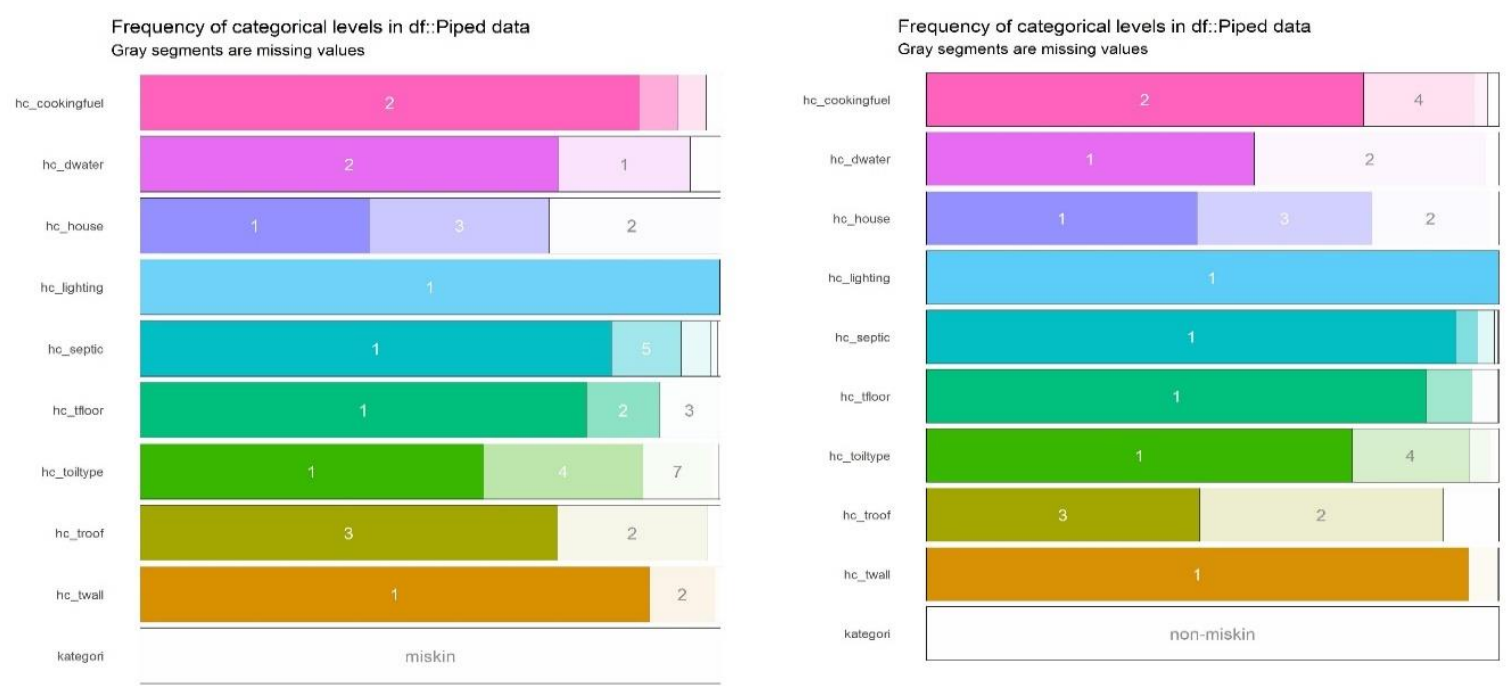

Sumber: Susenas, diolah

Gambar 5. Nilai Variabel Karakteristik Tempat Tinggal Pada Kelompok 40 persen Terbawah dan 60 persen teratas di Kota Jakarta Pusat

Gambar 5 menunjukkan pada beberapa variabel terdapat perbedaan nilai dan proporsi antara kelompok 40 persen terbawah dan 60 persen teratas di Jakart Pusat. Sebagian besar rumah tangga memasak dengan elpiji pada kelompok 40 persen terbawah, sedangkan pada kelompok 60 persen teratas sebagian rumah tangga memasak dengan elpiji dan sebagian lagi tidak memasak. Begitu juga dengan sumber air minum, sebagian besar rumah tangga pada kelompok 40 persen terbawah mengkonsumsi air kemasan isi ulang dan sebagian kecil mengkonsumsi air kemasan bermerek. Pola sumber air minum ini berkebalikan pada rumah tangga kelompok 60 persen teratas. Dengan adanya perbedaan siginifikan pada variabel penjelas antara kelompok 
rumah tangga 40 persen terendah dan kelompok rumah tangga 60 persen teratas di Kota Jakarta Pusat inilah turut berkontribusi pada hasil model yang terbentuk.

\section{KESIMPULAN}

Pemodelan machine learning dalam penelitian ini menghasilkan empat model machine learning untuk nilai pengeluaran ril perkapita (lrpcexp) terdiri dari model MARS, K-Nearest Neighbor, Decision Tree, dan Bagging. Dari seluruh kabupaten/kota, menunjukkan bahwa model MARS merupakan model yang seringkali outperform (unggul) dibandingkan model-model lain. Namun, di beberapa kabupaten/kota tertentu, model Bagging unggul. Performa model menunjukkan bahwa nilai inclusion error lebih rendah dibandingkan exclusion error. Artinya, rumah tangga kelompok 60 persen teratas yang masuk ke dalam kelompok 40 persen terbawah lebih sedikit dibandingkan rumah tangga kelompok 40 persen terbawah yang keluar. Nilai inclusion error terendah bisa mencapai 0,11 dan nilai exclusion error terendah mencapai 0,16 . Jika dibandingkan dengan pemodelan hasil PMT, pemodelan dengan menggunakan machine learning sedikit lebih unggul, di mana inclusion error terendah dari model PMT adalah sebesar 0,17 dan nilai exclusion error terendah mencapai 0,18 .

Hasil penelitian ini juga dapat digunakan sebagai justifikasi untuk memperkuat pemodelan PMT yang saat ini sudah diterapkan dalam pemeringkatan kesejahteraan rumah tangga dalam Basis Data Terpadu. Selain itu hasil penelitian ini sejalan dengan pandangan Adelman (2016) yang menyebutkan bahwa pemodelan machine learning merupakan tools yang dapat diterapkan untuk meningkatkan targetting dibandingkan dari model PMT.

Pada wilayah dimana nilai inclusion error dan exclusion error nya rendah, variabel tempat tinggal dan variabel aset memiliki variasi nilai yang jelas antara rumah tangga kelompok 40 persen terbawah dan 60 persen teratas (contoh di Kota Jakarta Pusat). Dengan adanya variasi tersebut, model bisa menghasilkan prediksi yang lebih baik sehingga mampu menurunkan inclusion dan exclusion error. Prediksi model machine learning bisa ditingkatkan dengan cara menambah variabel rumah tangga yang lebih informatif, seperti pada variabel aset sebaiknya ditanya tidak hanya status kepemilikan, namun jumlah aset yang dimiliki dan penambahan variabel yang mempu membedakan kedua kelompok tersebut. Karena pada prinsipnya, model akan bekerja lebih baik jika diberikan contoh data yang lebih beragam.

\section{DAFTAR PUSTAKA}

Adelman, Melissa. (2016). Targeting Poverty by Predicting Poverty. World Bank.

Avelita, B. (2016). Klasifikasi K-Nearest Neighbour. https://www.academia.edu/9131959

Breiman, L. (1996). Bagging predictors. Machine learning, 24(2), 123-140.

Coady, D., Grosh, M., \& Hoddinott, J. (2004). Targeting of Transfer in Developing Countries: Review of Lessons and Experience. Washington, D.C: The World Bank.

Di Franco, G., \& Santurro, M. (2021). Machine learning, artificial neural networks and social research. Quality \& Quantity, 55(3), 1007-1025.

Friedman, J.H. (1991). Multivariate Adaptive Regression Splines. The Annals of Statistics, Vol. 19, No. 1.

Jordan, M. I., \& Mitchell, T. M. (2015). Machine learning: Trends, perspectives, and prospects. Science, 349(6245), 255-260.

TNP2K. (2017). Basis Data Terpadu 2015, Untuk Memilah Penerima Manfaat Program Penanganan Fakir Miskin berdasarkan Kriteria Program.

Sharif, I. (2009). Building a targeting system for Bangladesh based on proxy means testing. World Bank, Human Development Network.

Sebastian, A. R., Shivakumaran, S., Silwal, A. R., Newhouse, D. L., Walker, T. F., \& Yoshida, N. (2018). A proxy means test for Sri Lanka. World Bank Policy Research Working Paper, (8605).

Yogi Yusuf, W. (2007). Perbandingan Performansi Algoritma Decision Tree C5. 0, CART, dan CHAID: Kasus Prediksi Status Resiko Kredit di Bank X. Islamic University of Indonesia.

World Bank (2015). Measuring income and poverty using Proxy Means Tests. World Bank. 